\title{
Apneustic breathing provoked by limbic influences
}

\author{
J Stewart, RS Howard, AG Rudd, C Woolf, RW Ross Russell
}

\begin{abstract}
Summary
We describe a 64-year-old man with cerebrovascular disease who had an acute stroke characterised by pseudobulbar palsy, facial weakness, and pyramidal signs. He developed frequent emotional outbursts followed by periods of apneusis. Between these episodes he breathed with a regular and unvarying rate and tidal volume. Autopsy showed extensive cortical, subcortical and pontine infarction. The respiratory pattern indicated a dissociation between voluntary and automatic pathways. The descending limbic pathways were preserved but an abnormal pattern of automatic breathing (ie, apneusis) occurred because of the presence of bilateral pontine infarction.
\end{abstract}

Keywords: apneustic breathing, limbic system, stroke

The neural control of ventilation may be considered to be subserved by three anatomically and functionally distinct pathways (table). Firstly, the automatic system, which depends on pontine and medullary areas and allows ventilation to be altered to maintain acid - base status and oxygenation according to metabolic demands. Automatic control is mediated by descending bulbospinal pathways in the ventrolateral brainstem and cord. Secondly, voluntary control allows modulation of respiration during wakefulness in response to actions such as talking, singing, and breath holding. This system is mediated by the cerebral cortex via the corticospinal tract. ${ }^{1,2}$ Finally, limbic respiratory and facial control (ie, ventilatory and facial responses to emotional stimuli), which is independent of automatic and voluntary control and depends upon a descending pathway which lies in the pontine tegmentum or basis pontis. ${ }^{3-7}$ In patients in whom voluntary pathways are interrupted by lesions affecting the descending corticospinal tract bilaterally, there is a strikingly regular and unvarying pattern during wakefulness and sleep with loss of ability to initiate any kind of volitional respiratory movement. However, there is preservation of respiratory modulation to emotional stimuli including laughter, crying and anxiety. ${ }^{1,2}$ In the absence of pulmonary disease, abnormal patterns of respiratory rate and rhythm are often a reflection of impaired automatic ventilatory control (box). In particular, apneustic breathing is characterised by sustained inspiratory cramps with a prolonged pause at full inspira- tion. This pattern is associated with bilateral tegmental infarcts or demyelinating lesions in the pons. ${ }^{8,9}$ We describe a patient with disturbances of both voluntary and automatic respiratory control in whom apneustic bursts were precipitated by emotional stimuli.

\section{Case report}

A 64-year-old right-handed West Indian man presented with a recurrent stroke after collapsing at his residential home. He had a history of evacuation of a right subdural haematoma nine years previously which had left him with a cognitive deficit and an IQ of 68. The signs from his subdural haematoma had largely resolved but three years later he had a stroke resulting in a left hemiparesis. He had been a life-long moderate smoker and a heavy drinker until five years previously. According to the staff at the residential home, he was mobile with the aid of a stick, and had no respiratory, cardiac or swallowing problems. He did not suffer from pathological crying or laughing, but was apathetic and abulic requiring verbal prompting for most activities of daily living.

Neurologically, following his collapse he was drowsy and obtunded but able to obey commands. There was no verbal response. Pupils were symmetrical $(2 \mathrm{~mm})$; he had no horizontal gaze to the left but oculovestibular reflexes were preserved. There was bilateral facial weakness, severe pseudobulbar palsy with absent pharyngeal reflex but a normal jaw jerk. He had a dense left hemiparesis and spontaneous movement in the right limbs, bilateral hyperreflexia and bilateral extensor plantar responses. Most of the signs on the left were longstanding. $\mathrm{He}$ also had bilateral pout and snout reflexes, but no grasp reflex.

On the second day after his stroke he was noted to have frequent outbursts of crying, each of which was followed by a period of apneusis lasting 15-40 seconds. His breathing between the emotional episodes was regular with an unvarying rate and tidal volume and no tendency to periodicity. This pattern was filmed during a one-hour period during which he had seven episodes of pathological crying, each of which was immediately followed by an apneustic pause. The pathological crying was triggered by questions of an emotive nature such as 'why are you in hospital?' and 'what is the matter?'. No spontaneous episodes were observed while he was lying undisturbed or being asked other questions of a non-emotive nature. Each episode was characterised by a 
Table Central pathways controlling respiration in man

\begin{tabular}{|c|c|c|c|}
\hline & Automatic & Voluntary & Limbic \\
\hline Function & Homeostatic control & Behavioural control & Emotional control \\
\hline Origin & Caudal pons \& medulla & $\begin{array}{l}\text { (Contralateral)motor cortex \& } \\
\text { cerebellum }\end{array}$ & ?Limbic cortex \\
\hline Pathway & $\begin{array}{l}\text { Ventrolateral spinal cord } \\
\text { (?reticulospinal) }\end{array}$ & $\begin{array}{l}\text { Corticobulbar \& corticospinal } \\
\text { (paramedian basis pontis) }\end{array}$ & Unknown (dorsolateral pons) \\
\hline Effect of lesions & $\begin{array}{l}\text { Abnormal patterns (box) } \\
\text { Central sleep apnoea }\end{array}$ & $\begin{array}{l}\text { Regular and unvarying } \\
\text { respiratory rate and tidal } \\
\text { volume }\end{array}$ & Unknown \\
\hline Causes of lesions & $\begin{array}{l}\text { Vascular } \\
\text { Bilateral cordotomy } \\
\text { Multiple sclerosis } \\
\text { Encephalitis } \\
\text { Paraneoplastic syndromes }\end{array}$ & $\begin{array}{l}\text { Vascular, eg, 'locked in syndrome', } \\
\text { multiple sclerosis }\end{array}$ & Vascular \\
\hline
\end{tabular}

\section{Patterns of abnormal automatic ventilatory control}

- primary central neurogenic hyperventilation: rapid, regular hyperventilation persisting in the face of alkalosis, elevated $\mathrm{pO}_{2}$, low $\mathrm{pCO}_{2}$ and in the absence of any pulmonary or airway disorder

- apneustic breathing: sustained inspiratory cramps with a prolonged pause at full inspiration or alternating brief end-inspiratory and expiratory pauses

- cluster breathing: respiration occurs in irregular bursts separated by variable periods of apnoea

- ataxic respiration: completely irregular respiratory cycle of variable frequency and tidal volme alternating with periods of apnoea

- central sleep apnoea: sudden or progressive decline in tidal volume and respiratory rate culminating in apnoea

Figure T2-weighted MRI showing changes compatible with extensive white matter disease and right basal pontine infarction

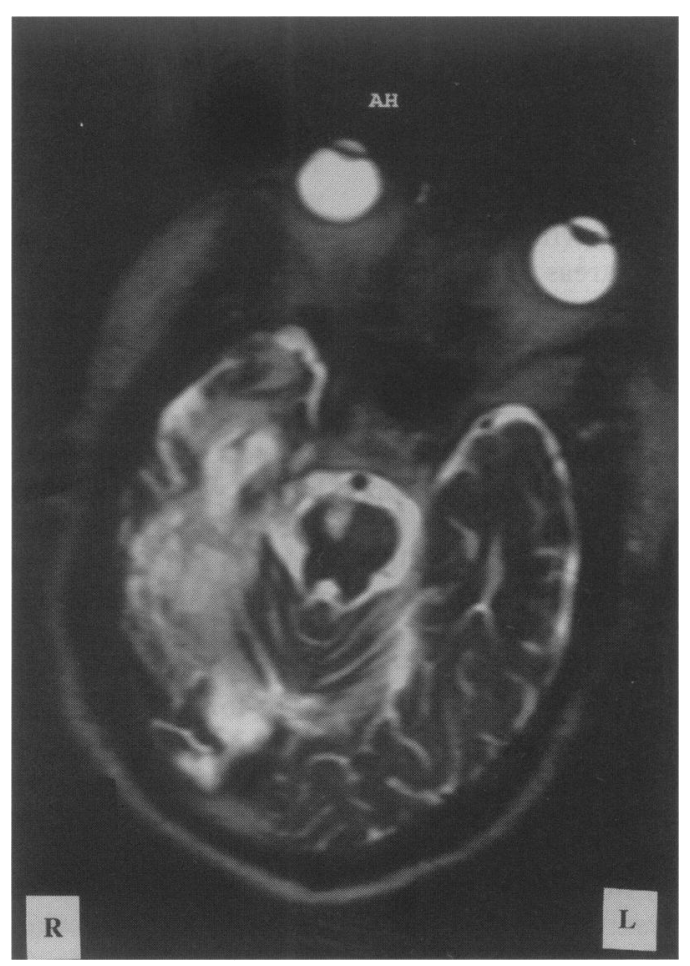

sudden change in facial expression to a grimace and sobbing with tears. Within a few seconds he developed an apneustic spasm. At the end of the apneustic period he exhaled and his facial expression returned to normal. For the remaining observed time, his breathing was regular with a respiratory rate of $22-24$ breaths/minute.

Systemic examination revealed a blood pressure of $180 / 100 \mathrm{mmHg}$, a clear chest and continuous oxygen saturation of $>97 \%$. His electrocardiogram showed sinus rhythm, but no acute ischaemic changes and his chest $\mathrm{X}$-ray showed clear lung fields. He had no systemic cause for an altered respiratory pattern which appeared to be neurogenic in origin. Magnetic resonance imaging (MRI) eight days following the stroke showed a right pontine infarct (figure), multiple small white matter lesions in the periventricular region, and lesions in the left cerebellum, right temporal and right occipital regions.

He improved slowly and was able to respond to simple commands. However, 10 days after admission he died, having suddenly become unresponsive and apnoeic. Autopsy showed multiple cortical and subcortical infarcts involving right temporo-parieto-occipital lobes, deep frontal white matter bilaterally, cerebellum and cerebral peduncles. Histological examination showed an old gliotic infarct in the right side of the basis pontis and a recent infarct on the left. The pyramids were shrunken and gliotic.

\section{Discussion}

In this patient the acute stroke was characterised by a pseudobulbar palsy with faciopharyngoglossomasticatory diplegia, emotional lability, pyramidal signs and automatic voluntary dissociation. In the presence of previous neurological signs it seems likely that the development of neurological signs was due to acute damage to corticobulbar fibres on one side when contralateral corticobulbar fibres had been previously interrupted. ${ }^{10}$ The acute event was likely to be a further small vessel ischaemic lesion in the left striatocapsular region or in the basis pontis. It remains uncertain whether the pathologically documented left basis pontis infarction was directly responsible for the presentation or was merely an agonal event. The severity of his impairment precluded a detailed respiratory study although a full clinical assessment and video recording were undertaken.

The functional interruption of voluntary respiratory control due to bilateral lesions of the descending pathway from the cerebral cortex in the corticospinal tracts resulted in a respiratory pattern largely determined by automatic control, leading to regular and unvarying 
rate and tidal volume. The descending limbic pathways were, apparently, not interrupted and emotional stimuli led to modulation of automatic respiration. Automatic respiratory control was, in turn, disrupted by the bilateral pontine lesions and this led to the development of apneustic breathing. The most striking feature of the apneustic pattern was that the

1 Plum F. Neurological integration of behavioural and metabolic control of breathing. In: Parker R, ed. Breathing: Hering-Breuer centenary symposium. London: Churchill 970; pp 314-27.

2 Howard RS, Newsom Davis J. The neural control of respiratory function. In: Crockard A, Hayward R, Hoff TT. eds Neurosurgery - the scientific basis of clinical practice Oxford: Blackwell Scientific Publications 1992; pp 318-36.

3 Munschauer FE, Mador MJ, Ahuja A, Jacobs L. Selective paralysis of voluntary but not limbically influenced automatic respiration. Arch Neurol 1991; 48: 1190-2.

4 Dawson K, Hourihan MD, Wiles CM, Chawla JC. Separation of voluntary and limbic activation of facial and respiratory muscles in ventral pontine infarction. $₹$ Neurol Neurosurg Psychiatry 1994; 57: 1281.

5 Heywood P, Howard RS, Murphy K, Corfield D, Morrell M, Guz A. Control of respiration in the clocked in syndrome'. F Neurol Neurosurg Psychiatry 1994; 57: 1293. inspiratory spasms could only be precipitated by emotional outburst. This finding would support the view that the descending limbic pathway directly influences automatic respiratory control. It also demonstrates that emotional input may precipitate apneustic respiration in the presence of disrupted automatic control due to pontine disease.

6 Topper R, Kosinski C, Mull M. Volitional type of facia palsy associated with pontine ischaemia. $\mathcal{F}$ Neurol Neurosurg Psychiatry 1995; 58: 732-4

7 Van Gijn J. Treating uncontrolled crying after stroke. Lance 1993; 48: $1190-2$.

8 Plum F, Alvord EC. Apneustic breathing in man. Arch Neurol 1964; 10: 101-12.

9 Howard RS, Wiles CM, Hirsch NP, Loh L, Spencer GT, Newsom Davis J. Respiratory involvement in multiple sclerosis. Brain 1992; 115: 479-94.

10 Besson G, Bogousslavsky J, Regli F, Maeder P. Acute pseudobulbar or suprabulbar palsy. Arch Neurol 1991; 48: 501-7.

11 Plum F, Posner JR. Diagnosis of stupor and coma. Philadelphia: FA Davis, 1983.

\title{
Syncope: driving advice is frequently overlooked
}

\author{
M MacMahon, D O’Neill, R A Kenny
}

\begin{abstract}
Summary
Consecutive referrals to a syncope clinic were asked about the frequency of enquiries about driving status by referring general practitioners and/or hospital specialists. Although $40 \%$ were drivers, only $13 \%$ of patients had been previously asked about driving, and $12 \%$ of drivers had experienced symptoms whilst driving. This represents an important oversight on the part of referring doctors.
\end{abstract}

Keywords: syncope, driving

Cardiovascular

Investigation Unit,

Department of

Medicine (Geriatric),

Royal Victoria

Infirmary, Newcastle

Upon Tyne NE1 4LP,

UK

M MacMahon

RA Kenny

Age-Related Health

Care, Meath Hospital,

Dublin 8, Ireland

D O'Neill

Correspondence to

Dr RA Kenny

Accepted 3 January 1996
Drivers who suffer from recurrent syncope may be a hazard on the road, yet the importance of syncope as a cause of driving accidents has received little attention in the literature. ${ }^{1,2}$ In the UK, it is the patient's responsibility to notify the Driving and Vehicle Licensing Agency (DVLA) if they have experienced an episode of loss of consciousness. ${ }^{3}$ Doctors should advise their patients of this. ${ }^{4}$ The DVLA may approach the attending physician for a report once the patient's consent has been obtained. A licence may be issued if the disorder can be controlled. ${ }^{4}$ Attending physicians are often unclear about their responsibilities in reporting syncope or advising about syncope and driving and physicians generally have scant knowledge of medical regulations on driving. ${ }^{2}$ Our objective was to determine how often patients with recurrent syncope were asked about driving status by either general practitioners or hospital specialists.

\section{Methods and results}

Consecutive referrals to the syncope clinic during a two-month period all completed a semi-structured questionnaire. Patients were asked about the frequency of enquiries about driving status by referring general practitioners and/or hospital specialists. Patients were also asked about their driving status and whether they considered that they were safe to drive. Presenting symptoms and their attributable causes were also detailed.

Sixty-four referrals were studied: median age 72 years (range 21 to 91 years), 34 male. All were secondary or tertiary referrals. Symptoms had been present for an average of four years (range one month to four years) with an

Hospital specialists who had investigated patients for symptoms of syncope

- general physicians $58 \%$

- cardiologists $27 \%$

- ear, nose and throat surgeons $9 \%$

- neurologists $4 \%$

- psychiatrists $2 \%$ 